\title{
An Integrated Soft Computing Approach to Hughes Syndrome Risk Assessment
}

\author{
João Vilhena ${ }^{1}$ M. Rosário Martins ${ }^{2} \cdot$ Henrique Vicente ${ }^{1,3}$ (D) José M. Grañeda ${ }^{4}$. \\ Filomena Caldeira $^{4} \cdot$ Rodrigo Gusmão ${ }^{4} \cdot J_{0 a ̃ o}$ Neves $^{5} \cdot$ José Neves $^{3}$
}

Received: 28 May 2016/Accepted: 11 January 2017

(C) Springer Science+Business Media New York 2017

\begin{abstract}
The AntiPhospholipid Syndrome (APS) is an acquired autoimmune disorder induced by high levels of antiphospholipid antibodies that cause arterial and veins thrombosis, as well as pregnancy-related complications and morbidity, as clinical manifestations. This autoimmune hypercoagulable state, usually known as Hughes syndrome, has severe consequences for the patients, being one of the main causes of thrombotic disorders and death. Therefore, it is required to be preventive; being aware of how probable is to have that kind of syndrome. Despite the updated of antiphospholipid syndrome classification, the diagnosis remains difficult to establish. Additional research on clinically relevant antibodies and standardization of their quantification are required in order to improve the antiphospholipid
\end{abstract}

This article is part of the Topical Collection on Systems-Level Quality Improvement.

José Neves

jneves@di.uminho.pt

João Vilhena

jmvilhena@gmail.com

M. Rosário Martins
mrm@uevora.pt
Henrique Vicente
hvicente@ uevora.pt
José M. Grañeda
graneda1@sapo.pt
Filomena Caldeira
filomenacaldeira1@gmail.com
Rodrigo Gusmão
gusmao.rodrigo@gmail.com

syndrome risk assessment. Thus, this work will focus on the development of a diagnosis decision support system in terms of a formal agenda built on a Logic Programming approach to knowledge representation and reasoning, complemented with a computational framework based on Artificial Neural Networks. The proposed model allows for improving the diagnosis, classifying properly the patients that really presented this pathology (sensitivity higher than $85 \%$ ), as well as classifying the absence of APS (specificity close to 95\%).

Keywords Antiphospholipid syndrome $\cdot$ Systemic autoimmune diseases · Artificial neuronal networks . Knowledge representation and reasoning $\cdot$ Logic programming
João Neves

joaocpneves@gmail.com

Departamento de Química, Escola de Ciências e Tecnologia, Universidade de Évora, 7000-671 Évora, Portugal

2 Departamento de Química, Laboratório HERCULES, Escola de Ciências e Tecnologia, Universidade de Évora, 7000-671 Évora, Portugal

3 Centro Algoritmi, Universidade do Minho, 4710-057 Braga, Portugal

4 Serviço de Patologia Clínica do Hospital do Espírito Santo de Évora EPE, Évora, Portugal

5 Drs. Nicolas \& Asp, Dubai, United Arab Emirates 